\title{
The adenomatous polyposis coli protein
}

\author{
I S Näthke
}

\begin{abstract}
Mutations in the adenomatous polyposis coli (APC) gene are associated with most colorectal cancers. The APC protein has been implicated in many aspects of tumour development. This article will discuss recent data suggesting that APC may have multiple functions in the cell. First, APC is a component of the Wnt signalling pathway; second, APC may have a role in cell migration; finally, APC may regulate proliferation and apoptosis.

(F Clin Pathol: Mol Pathol 1999;52:169-173)
\end{abstract}

Keywords: adenomatous polyposis coli gene; colorectal cancer; familial polyposis; Wnt signalling pathway

Mutations in the adenomatous polyposis coli (APC) gene are responsible for the familial form of colorectal cancer, familial polyposis (FAP). ${ }^{1}$ Patients heterozygous for a mutant APC gene develop numerous polyps throughout their intestinal tract, which progress into adenoma and malignancies if left untreated. ${ }^{1}$ In these polyps, the remaining wild-type copy of $\mathrm{APC}$ is lost. $^{23}$ Most sporadic intestinal tumours also lack expression of the full length APC protein. ${ }^{4}$ Introducing APC mutations into cells specifically in the gut epithelium is sufficient to cause polyp formation, whereas the introduction of one or several classic oncogenes does not have this effect. ${ }^{5}$ Thus, loss of APC appears to be an extremely early event that initiates colon cancer. ${ }^{6}$

A number of important cellular processes depend on APC function, as indicated by the variety of different APC binding partners. APC has emerged as a component of the Wnt signalling pathway. In addition, it is linked directly to the cytoskeleton and plays a role in the migration of epithelial cells and neuronal growth cones. Involvement of APC in progression through the cell cycle has also been suggested. Evidence for each of these roles will be discussed in turn.

11 May 1999

A

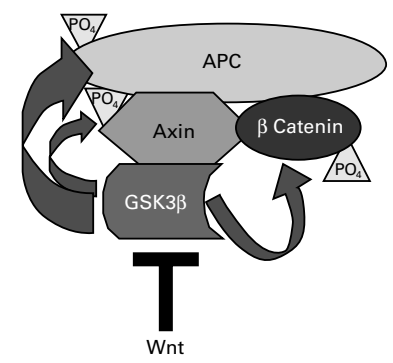

B

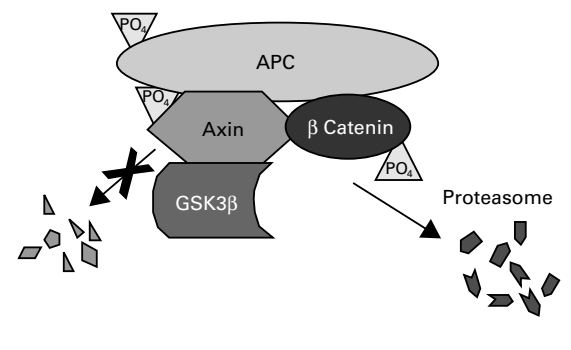

Figure 1 (A) Adenomatous polyposis coli (APC), axin, glycogen synthase kinase $3 \beta$ $(G S K 3 \beta)$, and $\beta$-catenin form a complex resulting in the phosphorylation of axin, $A P C$ and $\beta$-catenin. GSK3 $\beta$ activity is inhibited by Wnt signalling. (B) Phosphorylation of $\beta$-catenin leads to its degradation by the proteosome. The stability of axin is increased when it is phosphorylated by GSK3 $\beta$.

\section{APC in the Wnt signalling pathway}

The Wnt signalling pathway is crucial for embryonic development of the body axis in xenopus and the establishment of correct segment polarity in drosophila. ${ }^{78}$ Binding of Wnt to its cell surface receptor, frizzled, causes inactivation of the protein kinase, glycogen synthase kinase $3 \beta(\mathrm{GSK} 3 \beta){ }^{8}$ GSK $3 \beta$ is one component of a large protein complex also containing APC, axin, and $\beta$-catenin (fig $1 \mathrm{~A}) .^{9-15}$ In the absence of Wnt signalling, GSK $3 \beta$ phosphorylates APC and $\beta$-catenin. ${ }^{8}$ Axin facilitates GSK3 $\beta$ phosphorylation of $\mathrm{APC}$ and $\beta$-catenin in vitro and thus may act as a scaffold for this complex. ${ }^{10}$ Most importantly, phosphorylation of $\beta$-catenin leads to its ubiquitination and targeting to the proteasome, resulting in $\beta$-catenin degradation. ${ }^{16}$ Degradation of axin, on the other hand, is decreased in response to its phosphorylation by GSK3 $\beta$ (fig 1B). ${ }^{17}$ This ensures that, in the absence of wnt signalling, axin is available for the axin-APC$\beta$-catenin-GSK3 $\beta$ complex to support the degradation of $\beta$-catenin. APC protein interacts directly with $\beta$-catenin, ${ }^{18}{ }^{19}$ and this interaction is required for proteasome mediated degradation of $\beta$-catenin. ${ }^{20}$ However, APC is not required for $\beta$-catenin phosphorylation in vitro. It is possible that APC provides a link between $\beta$-catenin and the ubiquitinating enzymes that are required for the targeting of $\beta$-catenin to the proteasome. Recently, the $\beta$-TrCP protein was identified as a negative regulator of the Wnt pathway in xenopus. ${ }^{21}$ The sequence of $\beta$-TrCP contains motifs that are known to be involved in binding to ubiquinating enzymes, ${ }^{21}$ and it will be of great interest to test the association of APC with $\beta$-TrCP or its homologues.

Wnt signalling inactivates GSK $3 \beta$ and leads to the accumulation of free intracellular $\beta$-catenin that can bind to the Tcf/Lef ( $T$ cell factor/lymphoid entrancer factor) family of HMG box transcription factors. ${ }^{22-28}$ The $\beta$-catenin-transcription factor complex regulates transcription of target genes including c-myc. ${ }^{28} 29$ This link between $\beta$-catenin and c-myc activation provides one model for how loss of APC in the gut epithelium may lead to transformation. Loss of APC function would prevent $\beta$-catenin degradation so that concentrations of free $\beta$-catenin would increase and be available for Tcf/Lef activation. This would result in the inappropriate transcription of genes like c-myc and lead to transformation. This model suggests that the expression of genes regulated by $\mathrm{Tcf} /$ Lef is tightly controlled. Indeed, Tcf negative mice lack proliferative compartments and do not develop intestinal crypts. $^{30}$ 
But is APC function really that simple? Overexpression of the APC gene specifically in gut epithelium in vivo does not lead to a decrease of $\beta$-catenin. ${ }^{31}$ Ectopic expression of the APC gene in developing xenopus causes axis duplication, ${ }^{32}$ the same phenotype achieved by ectopic expression of the $\beta$-catenin gene. ${ }^{33}$ Moreover, levels of $\beta$-catenin gene expression are not affected in developing drosophila mutants that lack APC. ${ }^{34}$ In fact, these flies develop normally and have minor defects, mostly in the central nervous system (CNS). ${ }^{34}$

Normal intestinal epithelial cells do not appear to contain appreciable amounts of free $\beta$-catenin, which is the pool of $\beta$-catenin that is regulated by the APC-axin complex; untransformed cultured epithelial cells also do not contain free $\beta$-catenin. ${ }^{35}$ On the other hand, transformed cells contain a large pool of free $\beta$-catenin that is sensitive to downregulation when wild-type APC concentrations are increased. ${ }^{20}{ }^{35}$ The inability of mutant APC to decrease $\beta$-catenin concentrations may allow this large pool of $\beta$-catenin to remain unchecked and hence contribute to the progression of colorectal cancer at later stages. How mutations in APC are involved in the initial steps of polyp formation may in turn be related to the role played by APC in the migration of cells.

\section{APC in cell migration and adhesion}

The APC protein can bind to and bundle microtubules in vitro and induce their assembly. ${ }^{36}{ }^{37}$ The C-terminal domain of APC contains a tau protein-like domain and colocalises with microtubules when overproduced in tumour cells. ${ }^{36-38}$ In epithelial cells, endogenous APC localises to the tips of microtubules invading areas of the membrane involved in migration. $^{39}$ Depolymerising microtubules using nocodazole inhibits this type of migration in epithelial cells and disrupts APC localisation. ${ }^{39}$ These observations have led to the hypothesis that the APC protein is involved in stabilising microtubules in specific areas of the cell, resulting in the formation of stable cellular protrusions that are actively involved in migration.

This type of migration may be particularly important in neurons, where a requirement for microtubule dynamics in the extension and guidance of growth cones has been well documented. ${ }^{40}$ In cultured neuronal cells, the APC protein is enriched in growth cones and this distribution requires an intact microtubule network. ${ }^{41}{ }^{42}$ The synthesis of APC in the nervous system coincides with the ability of neurons to undergo morphological changes, such as process extension and synapse formation, and its pattern of synthesis parallels that of microtubule associated protein 2 (MAP2) and other microtubule associated proteins. ${ }^{43}$ Similarly, PC-12 cells treated with nerve growth factor (NGF) increased the production of APC as they extended nerve growth cone-like structures. ${ }^{44}$ In drosophila, loss of APC results in CNS defects that may be related to the inability of specific neuronal structures to elongate properly, consistent with a cytoskeletal defect. ${ }^{34}$ In this context, it is noteworthy that the incidence of neuronal brain tumours is significantly raised in patients with familial polyposis, ${ }^{45}$ suggesting that loss of APC function might be related to neuronal abnormalities in humans. All these data are consistent with the idea that APC plays an important role in cell migration involving microtubules, which is particularly important in neuronal and epithelial cell migration.

The mutations described in patients with FAP usually consist of truncations leading to loss of the C-terminal region of APC, which contains the microtubule binding site. ${ }^{4}$ This is conceivably the reason for polyp formation, the earliest detectable change in patients with FAP. Such mutant APC proteins cannot bind to and stabilise microtubules; this might compromise the migration of gut epithelial cells and prolong their residence near the proliferative environment of the crypt, and increase the time they are exposed to the toxins present in the gut. Receiving inappropriate proliferative signals in the crypt might cause abnormal growth of the polyps and increased exposure to the toxins present in the gut may lead to the accumulation of additional mutations that ultimately result in transformation. At this later stage, it is likely that there is an increase in the pool of free $\beta$-catenin, which cannot be regulated by the mutant APC, so that increased Tcf/Lef transcriptional activation occurs, further advancing transformation.

Some direct evidence for a role of APC in the migration of gut epithelial cells is now available. In the intestinal epithelium, each proliferative crypt supplies differentiating enterocytes to surrounding villi. ${ }^{46}$ Normally, enterocytes migrate upwards in orderly columns and do not mix with cells derived from neighbouring crypts. ${ }^{31}$ When the APC gene was overexpressed in gut epithelium, cells migrated in a disorderly manner, so that mixing between enterocytes from neighbouring crypts was observed. ${ }^{31}$ It is possible that the observed change in cell migration was caused by a decrease in intracellular adhesion that may have been induced by excess APC. However, the expression of E-cadherin and catenins, and the distribution of these proteins in cells overproducing APC were indistinguishable from neighbouring wild-type cells. ${ }^{31}$ In addition, barrier function in tissues overexpressing the APC gene appeared to be perfectly intact. ${ }^{31}$ These observations suggest that excess APC did not cause alterations in intracellular adhesion and are consistent with a direct role for APC in regulating the migration of enterocytes in the gut.

One question that has emerged is how the interaction between APC and microtubules is related to the interaction of APC with the axin- $\beta$-catenin complex. A non-degradable form of $\beta$-catenin accumulated in APC containing clusters in epithelial cells. ${ }^{47}$ Cells producing this stabilised form of $\beta$-catenin did not migrate normally, and neither were they able to extend stable protrusions to migrate into a surrounding matrix when treated with 
scatter factor. ${ }^{48}$ These observations suggest that a stable complex of non-degradable $\beta$-catenin with APC caused a decrease in the ability of APC to interact with microtubules, so that the formation of stable cellular protrusions was inhibited. This could explain why overproduction of this non-degradable form of $\beta$-catenin in gut epithelium correlated with decreased migration in intestinal cells in vivo. ${ }^{49}$ An alternative interpretation of these observations is that overexpression of the $\beta$-catenin gene caused an increase in intercellular adhesion, which led to the observed decrease in migration. Indeed, overexpressing the $\beta$-catenin gene in gut epithelium led to an apparent increase in E-cadherin. However, overexpression of the E-cadherin gene specifically in gut epithelium affected not only migration but also proliferation and apoptosis of enterocytes. ${ }^{50}$ This indicates that the upregulation of E-cadherin induced by the overproduction and stabilisation of $\beta$-catenin in gut epithelium does not simply mimic the upregulation of E-cadherin, and that the interaction of the additional $\beta$-catenin with APC may contribute directly to the observed decrease in migration. However, the confirmation of $\beta$-catenin as a possible key regulator of $\mathrm{APC}-$ microtubule interactions will require in vitro analysis.

It is important to note that the upregulation of $\beta$-catenin production in the studies described above did not lead to the formation of polyps or adenoma, as would be expected if excessive amounts of $\beta$-catenin were available for binding to $\mathrm{Tcf} / \mathrm{Lef}$ transcription factors. One likely explanation is that the additional $\beta$-catenin was not available for binding to the Tcf/Lef transcription factors because it was bound to E-cadherin. The observed decrease in enterocyte migration should also lead to the formation of polyps if the model suggested above is correct. However, the observed increase in cell adhesion is likely to have obscured any effect on cell migration, illustrating how difficult it is to separate cell adhesion and migration in the context of the gut epithelium, where these processes are tightly coupled.

Further support for a role for APC in cell migration comes from examinations of the earliest detectable polyps in Min (multiple intestinal neoplasia) negative mice, which are heterozygous for mutated APC and develop multiple polyps throughout their intestinal tract. ${ }^{51}$ The initial step in polyp formation appears to be the formation of outpocketing pouches from the proliferative zone, which then migrate backwards. $^{52}$ This morphology of early polyps is consistent with a defect in their migration. Furthermore, the migration of enterocytes in these mice was reduced by $25 \%$ when compared with that of normal litter mates..$^{53}$ Importantly, restoring the migration rate of Min negative enterocytes to normal levels by administering the non-steroidal antiinflammatory, sulindac, led to a significant reduction in the number of polyps. ${ }^{534}$

\section{APC in proliferation and apoptosis}

Transformation is often associated with increased cell proliferation and/or decreased apoptosis, and a role for APC in both of these processes has been postulated. So far, no consensus regarding the effect of APC on apoptosis has been reached because both induction and inhibition of apoptosis by APC have been described. ${ }^{55-57}$ Most importantly, however, overexpressing the APC gene in normal intestinal epithelia does not alter the rates of proliferation or apoptosis, ${ }^{31}$ and cells in the earliest detectable polyps show no changes in proliferation or apoptosis when compared with normal tissue. ${ }^{52}$

APC has multiple consensus sites for cyclin dependent kinases (CDKs) and is a substrate for these kinases. ${ }^{58}$ APC overexpression led to cell cycle arrest in tissue culture cells. ${ }^{59}$ Mutant APC induced the arrest less efficiently and the arrest could be overcome by the overexpression of CDK genes. ${ }^{59}$ This is consistent with the finding that overexpression of APC appeared to downregulate cyclin-CDK complex activity. ${ }^{59}$ One trivial explanation for these observations is that excessive amounts of the CDK consensus sites contained in the APC protein diminished the amount of CDK available for other substrates, thus leading to cell cycle arrest. Because no difference in APC phosphorylation was observed in cells at different stages of the cell cycle, the involvement of APC in CDK mediated cell cycle regulation remains unclear. ${ }^{58}$

Additional evidence for a possible role for APC in the cell cycle is the discovery of another APC-binding protein, EB1.$^{60}$ The EB1 protein localises to interphase and mitotic microtubules, ${ }^{61}$ and is required for a cell cycle check point in yeast. ${ }^{62}$ It is not kown whether the binding of EB1 to APC is related to the role of EB1 in the cell cycle because the association of EB1 with microtubules does not depend on APC and a homologue of APC has not been identified in yeast. ${ }^{61}$ However, it is possible that $\mathrm{EB} 1$ is sufficient for the simpler cell cycle machinery of yeast, whereas both APC and $\mathrm{EB} 1$ are required in more complex mammalian systems. In summary, APC may play a role in both apoptosis and cell cycle regulation. However, in vivo data suggest that in the context of a normal epithelium, APC does not affect either of these processes.

\section{Summary and conclusions}

APC is important for tissue homeostasis and loss of its functions is associated with familial and sporadic cases of colon cancer. It is a large protein with many binding partners, and many more are likely to be identified over the next few years. The data so far support at least two major roles for APC: a role in cell migration via its direct link with the cytoskeleton and a role in gene expression via its ability to regulate the amount of $\beta$-catenin available for regulating transcription (fig 2). A role in regulating cell migration could explain the early stages of disease. A migration defect could lead to the accumulation of cells to form polyps, the earliest detectable change in the progression to 


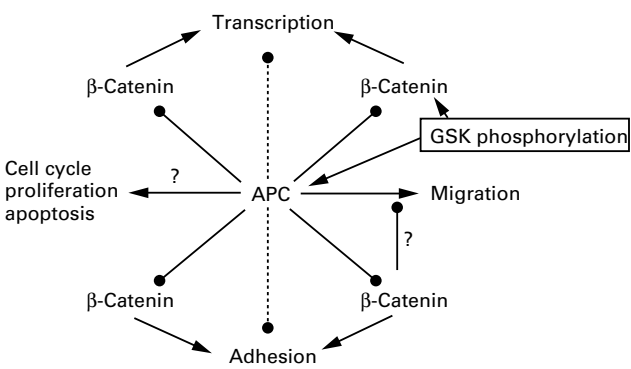

Figure 2 The adenomatous polyposis coli (APC) protein can regulate the turnover of $\beta$-catenin and thus can indirectly affect gene transcription and cell adhesion (indicated by the dotted lines). The interaction between $A P C$ and $\beta$-catenin is regulated by glycogen synthase kinase $3 \beta$ (GSK3 $\beta$ ) phosphorylation. APC may also have roles in cell proliferation and apoptosis. Arrows denote enhancing or positive effects, whereas inhibitory or negative effects are denoted by lines ending in closed circles.

colon cancer. A role in regulating $\beta$-catenin concentrations may be important in the later stages in colorectal cancer. It is also possible that in normal tissue, APC participates in additional signalling pathways and functions in the regulation of the cell cycle and apoptosis.

APC has been referred to as a "gatekeeper" in the progression of colon cancer. ${ }^{63}$ In fact, it may hold the key to several gates through which cells pass on their way to malignancy. It is in a key position to regulate the balance between cell adhesion and migration and may also be involved in proliferation and apoptosis. The balance between these processes is particularly crucial in developing tissues and in the maintenance of renewing tissues, such as the gut, which explains why APC loss manifests itself in this organ most strongly.

Studies in the author's laboratory are supported by a Burroughs Wellcome Fund Career Development Award and a Cancer Wellcome Fund Career Development Award and a Cancer Swedlow, B Spruce, S Bekir, and J Zumbrunn for critical reading of the manuscript.

1 Groden J, Thilveris A, Samowitz W, et al. Identification and characterization of the familial adenomatous polyposis coli gene. Cell 1991;66:589-600.

2 Levy DB, Smith KJ, Beazer-Barclay Y, et al. Inactivation of both APC alleles in human and mouse tumors. Cancer Res 1994;54:5953-8.

3 Luongo C, Moser AR, Gledhill S, et al. Loss of $\mathrm{APC}^{+}$in intestinal adenomas from Min mice. Cancer Res 1994;54: 5947-52.

4 Polakis P. Mutations in the APC gene and their implications for protein structure and function. Curr Opin Genet Dev 1995;5:66-71.

$5 \mathrm{Kim}$ SH, Roth KA, Moser AR, et al. Transgenic mouse models that explore the multistep hypothesis of intestinal neoplasia. F Cell Biol 1993;123:877-93.

6 Powell SM, Zilz N, Beazer-Barclay Y, et al. APC mutations occur early during colorectal tumorigenesis. Nature 1992; occur early

7 Siegfried E, Perrimon N. Drosophila wingless: a paradigm for the function and mechanism of Wnt signaling. BioEssays 1994;16:395-404.

8 Dierick H, Besjovec A. Cellular mechanisms of wingless/ Wnt signal transduction. Curr Top Dev Biol 1999;43:15390 .

9 Behrens J, Jerchow BA, Wurtele M, et al. Functional interaction of an axin homolog, conductin, with betacatenin, APC, and GSK3beta. Science 1998;280:596-9.

10 Hart MJ, de los Santos R, Albert I, et al. Downregulation of $\beta$-catenin by human axin and its association with the APC tumor suppressor, $\beta$-catenin and GSK3 $\beta$. Curr Bio 1998;8:573-81.

11 Ikeda S, Kishida S, Yamamota $\mathrm{H}$, et al. Axin, a negative regulator of the Wnt signaling pathway, forms a complex with GSK-3beta and beta-catenin and promotes GSK3beta-dependent phosphorylation of beta-catenin. EMBO 31998;17:1371-84.

12 Itoh K, Krupnik VE, Sokol SY. Axis determination in xenopus involves biochemical interactions of axin, glycogen synthase kinase 3 and b-catenin. Curr Biol 1998;8:591-4.
13 Nakumura T, Hamada F, Ishidate $\mathrm{T}$, et al. Axin, an inhibitor of the Wnt signalling pathway, interacts with beta-catenin, of the Wnt signalling pathway, interacts with beta-catenin, GSK-3beta and APC and redi $1998 ; 3: 395-403$.

14 Sakana C, Weiss JB, Lewis LT. Bridging of beta-catenin and glycogen synthase kinase-3beta by axin and inhibition of beta-catenin-mediated transcription. Proc Natl Acad Sci USA 1998;95:3020-3.

15 Yamamoto H, Kishida S, Uochi T, et al. Axil, a member of the axin family, interacts with both glycogen synthase kinase 3 beta and beta-catenin and inhibits axis formation in xenopus embryos. Mol Cell Biol 1998;18:2867-75.

16 Aberle H, Bauer A, Stappert J, et al. Beta-catenin is a target for the ubiquitin-proteasome pathway. EMBO $\mathcal{F} 1997 ; 16$ : 3797-804

17 Yamamoto H, Kishida S, Kishida M, et al. Phosphorylation of axin, a Wnt signal negative regulator, by glycogen synthase kinase-3 3 regulates its stability. $₹$ Biol Chem 1999 ; 274:10681-4.

18 Rubinfeld B, Souza B, Albert I, et al. Association of the APC gene product with $\beta$-catenin. Science 1993;262:1731-4.

19 Su L-K, Vogelstein B, Kinzler KW. Association of the APC tumor suppressor protein with catenins. Science 1993;262: $1734-7$

20 Munemitsu S, Albert I, Souza B, et al. Regulation of intracellular beta-catenin levels by the adenomatous polyposis coli (APC) tumor-suppressor protein. Proc Natl Acad Sci USA 1995;92:3046-50.

21 Marikawa Y, Ellinson RP. $\beta$-TrCP is a negative regulator of the Wnt/ $\beta$-catenin signaling pathway and dorsal axis formation in xenopus embryos. Mech Dev 1998;77:75-80.

22 Papkoff J, Rubinfeld B, Schryver B, et al. Wnt-1 regulates free pools of catenins and stabilizes APC-catenin complexes. Mol Cell Biol 1996;16:2128-34

23 Behrens WJ, von Kries JP, Kuhl M, et al. Functional interaction of beta-catenin with the transcription factor LEF-1. Nature 1996;382:638-42.

24 Hsu SC, Galceran J, Grosschedl R. Modulation of transcriptional regulation by LEF-1 in response to Wnt-1 signaling and association with beta-catenin. Mol Cell Biol 1996;18:4807-18

25 Huber O, Korn R, McLaughlin J, et al. Nuclear localization of beta-catenin by interaction with transcription factor LEF-1. Mech Dev 1996;59:3-10.

26 Molenaar $M$, van de Wetering $M$, Oosterwege $M$, et al. XTcf-3 transcription factor mediates beta-catenin-induced axis formation in xenopus embryos. Cell 1996;86:391-9.

27 Porfiri E, Rubinfeld B, Albert I, et al. Induction of a beta-catenin-LEF-1 complex by wnt-1 and transforming mutants of beta-catenin. Oncogene 1997;15:2833-9.

28 Ben-Ze'ev A, Geiger B. Differential molecular interactions of $\beta$-catenin and plakoglobin in adhesion, signaling and cancer. Curr Biol 1998;10:629-39.

29 He TC, Sparks AB, Rago C, et al. Identification of c-myc as a target of the APC pathway. Science 1998;10:629-39.

30 Korinek V, Barker N, Moerer P, et al. Depletion of epithelial stem-cell compartments in the small intestine of mice lacking Tcf-4. Nat Genet 1998;4:379-83.

31 Wong $\mathrm{MH}$, Hermiston ML, Gordon JI. Forced expression of the tumor suppressor adenomatous polyposis coli protein induced disordered cell migration in the intestinal epithelium. Proc Natl Acad Sci USA 1996;93:9588-93.

32 Vleminckx $\mathrm{K}$, Wong $\mathrm{E}$, Guger $\mathrm{K}$, et al. Adenomatous polyposis coli tumor suppressor protein has signaling activity in Xenopus laevis embryos resulting in the induction of an ectopic dorsoanterior axis. F Cell Biol 1997;136:411-20.

33 Funayama N, Fagotto F, McCrea P, et al. Embryonic axis induction by the armadillo repeat domain of beta-catenin:
evidence for intracellular signaling. 7 Cell Biol 1995;128: evidence

34 Hayashi S, Rubinfeld B, Souza B, et al. A drosophila homolog of the tumor suppressor gene adenomatous polyposis coli down-regulates beta-catenin but its zygotic expression is not essential for the regulation of armadillo. Proc Natl Acad Sci USA 1997;94:242-7.

35 Stewart DB, Nelson WJ. Identification of four distinct pools of catenins in mammalian cells and transformationdependent changes in catenin distributions among these pools. F Biol Chem 1997;272:29652-62.

36 Munemitsu S, Souza B, Müller O, et al. The APC gene product associates with microtubules in vivo and promotes their assembly in vitro. Cancer Res 1994;54:3676-81.

37 Smith KJ, Levy DB, Maupin P, et al. Wild-type but not mutant APC associates with the microtubule cytoskeleton. Cancer Res 1994;54:3672-5.

38 Deka J, Kuhlmann DJ, Muller O A domain within the tumor suppressor protein APC shows very similar biochemical properties as the microtubule-associated protein tau. Eur f Biochem 1998;253:591-7.

39 Näthke IS, Adams CL, Polakis P, et al. The adenomatous polyposis coli tumor suppressor protein localizes to plasma membrane sites involved in active cell migration. $f$ Cell Biol 1996;134:165-79.

40 Tanaka E, Sabry J. Making the connection: cytoskelatal earrangements during growth cone guidance. Cell 1995; 83:171-6.

41 Morrison EE, Askham J, Clissold P, et al. Expression of beta-catenin and the adenomatous polyposis coli tumour suppressor protein in mouse neocortical cells in vitro. Neurosci Lett 1997;235:129-32.

42 Morrison EE, Askham JM, Clissold P, et al. The cellular distribution of the adenomatous polyposis coli tumour tribution of the adenomatous polyposis coli tumour
suppressor protein in neuroblastoma cells is regulated by microtubule dynamics. Neuroscience 1997;81:553-63. 
43 Bhat RV, Baraban JM, Johnson RC, et al. High levels of expression of the tumor suppressor gene APC during development of the

44 Dobashi Y, Bhattacharjee RN, Toyoshima K, et al. Upregulation of the APC gene product during neuronal differentiation of rat pheochromocytoma PC12 cells. Biochem Biophys Res Commun 1996;224:479-83.

45 Hamilton SR, Liu B, Parsons RE, et al. The molecular basis of Turcot's syndrome [see comments]. N Engl f Med 1995; 332:839-47.

46 Hermiston ML, Simon TC, Crossman MW, et al. Model systems for studying cell fate specification and differentiation in the gut epithelium. In: Johnson LR, ed. Physiology of the gastrointestinal tract, 3rd ed. New York: Raven Press, 1994:521-69.

47 Barth AIM, Pollack AL, Altschuler Y, et al. $\mathrm{NH}_{2}$-terminal deletion of $\beta$-catenin results in stable colocalization of mutant $\beta$-catenin with APC protein and altered MDCK cell adhesion. F Cell Biol 1997;136:693-706.

48 Pollack AL, Barth AIM, Altschuler Y, et al. Dynamics of Pollack AL, Barth AIM, Altschuler Y, et al. Dynamics of
$\beta$-catenin interactions with APC protein regulate epithelial

49 Wong MH, Rubinfeld B, Gordon JI. Effects of forced expression of an $\mathrm{NH}_{2}$-terminal truncated $\beta$-catenin on mouse intestinal epithelial homeostasis. F Cell Biol 1998; 141:765-77.

50 Hermiston ML, Wong MH, Gordon JI. Forced expression of E-cadherin in the mouse intestinal epithelium slows cell migration and provides evidence for nonautonomous regulation of cell fate in a self-renewing system. Genes Der 1996;10:985-96.

51 Moser AR, Dove WF, Roth KA, et al. The Min (multiple intestinal neoplasia) mutation: its effect on gut epithelial cell differentiation and interaction with a modifier system. f Cell Biol 1992;116:1517-26.

52 Oshima H, Oshima M, Kobayashi M, et al. Morphological and molecular processes of polyp formation in Apc and molecular processes of polyp
53 Mahmoud NN, Boolbol SK, Bilinski RT, et al. APC gene mutation is associated with a dominant-negative effect upon intestinal cell migration. Cancer Res 1997;57:504550

54 Chiu CH, McEntee MF, Whelan J. Sulindac causes rapid regression of preexisting tumors in $\mathrm{Min} /+$ mice independent of prostaglandin synthesis. Cancer Res 1997;57:426773.

55 Morin PJ, Vogelstein B, Kinzler KW. Apoptosis and APC in colorectal tumorigenesis. Proc Natl Acad Sci USA 1996;93: 7950-4.

56 Mahmoud NN, Boolbol SK, Dannenberg AJ, et al. The sulfide metabolite of sulindac prevents tumors and restores enterocyte apoptosis in a murine model of familial polyposis. Carcinogenesis 1998;19:87-91.

57 Ahmed Y, Hayashi S, Levine A, et al. Regulation of armadillo by drosophila APC inhibits neuronal apoptosis during retinal development. Cell 1998;93:1171-82.

58 Trzepacz C, Lowy AM, Kordich JJ, et al. Phosphorylation of the tumor suppressor adenomatous polyposis coli (APC) by the cyclin-dependent kinase p34cdc2. I Biol Chem 1997;272:21681-4.

59 Baeg GH, Matsumine A, Kuroda T, et al. The tumor suppressor gene product APC blocks cell cycle progression from $\mathrm{G}_{0} / \mathrm{G}_{1}$ to $\mathrm{S}$ phase. $E M B O \mathcal{F} 1995 ; 14: 5618-25$.

60 Su L-K, Burrell M, Hill DE, et al. APC binds to the novel protein EB1. Cancer Res 1995;55:2972-7.

61 Berrueta L, Kraeft SK, Tirnauer JS, et al. The adenomatous polyposis coli-binding protein EB1 is associated with cytoplasmic and spindle microtubules. Proc Natl Acad Sci USA 1998;95:10596-601

62 Muhua L, Adames NR, Murphy MD, et al. A cytokinesis checkpoint protein requiring the yeast homologue of an APC-binding protein. Nature 1998;393:487-91.

63 Kinzler WK, Vogelstein B. Lessons from hereditary colorectal cancer. Cell 1996;87:159-70. 